\title{
PRODUÇÃO EXTEMPORÂNEA DE AMORA-PRETA ${ }^{1}$
}

\author{
LUIS EDUARDO CORRÊA ANTUNES ${ }^{2}$, RENATO TREVISAN ${ }^{3}$, \\ EMERSON DIAS GONÇALVES ${ }^{3}$, RODRIGO CEZAR FRANZON ${ }^{4}$
}

\begin{abstract}
RESUMO - A fruticultura mineira vem crescendo e diversificando-se nos últimos anos. A amora-preta surge como opção desta diversificação, e o conhecimento do comportamento desta espécie, em Minas Gerais, se faz de suma importância. O objetivo deste trabalho foi o de avaliar a influência da poda de verão na produção extemporânea de variedades de amora-preta no Planalto de Poços de Caldas-MG. O trabalho foi realizado na Fazenda Experimental (FECD) da Epamig, em Caldas-MG. As análises foram realizadas na coleção de variedades mantidas na FECD. Foram avaliadas as seguintes características: período de colheita, peso médio de fruto, produção média por planta e por hectare de 7 variedades (Brazos, Comanche, Guarani, Tupy, Cherokee, Caingangue e Ébano) e uma seleção (97). Concluiu-se que a produção extemporânea, induzida pela poda de verão, influiu negativamente em todas as características avaliadas. Entre as variedades que mais produziram fora de época, Tupy $(2,93 \mathrm{t} / \mathrm{ha})$ e Comanche (3,26 t/ha) foram as que mais se destacaram.
\end{abstract}

Termos para indexação: Rubus spp, pequenas frutas, produção fora de época, poda.

\section{OFF SEASON PRODUCTION OF BLACKBERRIES VARIETIES}

\begin{abstract}
The fruit culture, in the State of Minas Gerais, has been increased and diversified considerably, during the last years. Blackberry appeared as an important option to fruit growers; however there are no trials performed in that State. The objective of this work was to evaluate the summer pruning effects on off season production of blackberries varieties. This work was carried out in Epamig - "Fazenda Experimental" in Caldas, state of Minas Gerais, Brazil. Fruit weight, estimated production and productivity per plant and per hectare (ha) were evaluated for seven cultivars (Brazos, Comanche, Ébano, Caingangue, Guarani, Tupy and Cherokee) and one selection (97). The results lead to conclude that summer pruning induced less production in all varieties. Highest off season production was obtained in 'Comanche' ( 3 , 26 t/ha), followed by 'Tupy' (2,93 t/ha).
\end{abstract}

Index terms: Rubus spp, small fruit, off season production, pruning.

\section{INTRODUÇÃO}

Tendo em vista a baixa remuneração e o baixo poder aquisitivo dos agricultores do Planalto de Poços de Caldas, Estado de Minas Gerais, proveniente da produção de leite e de grãos, torna-se necessário identificar alternativas que permitam, ao mesmo tempo, melhorar o padrão de vida dos agricultores, gerar empregos e aumentar a arrecadação dos municípios. A atividade frutícola identifica-se perfeitamente com o perfil da pequena propriedade rural, uma vez que as características de topografia dos municípios do Planalto de Poços de Caldas, no sul de Minas Gerais, dificultam a mecanização agrícola, fator indispensável na produção de grãos (Antunes et al., 2000 a).

Quanto à amora-preta, estima-se que existam 300 ha plantados desta rosácea no sul de Minas, região de Jundiaí, Curitiba e Palmas no Paraná, com cultivos em Santa Catarina e Rio Grande do Sul. Estes cultivos, em sua maioria, são em pequenas propriedades. A fruta fresca tem grande mercado. Em algumas regiões, como as de Pelotas, Antônio Prado e Vacaria, pequenas cooperativas já transformam a produção em geléias e sucos (Antunes, 2005).

Entre as alternativas de exploração frutícola para a região, as de clima temperado se destacam. Das mais promissoras, a amorapreta vem despertando interesse dos produtores locais pelas qualidades de seus frutos e rusticidade de manejo, complementando a produção tradicional de morangos (Duarte Filho et al., 2001). Para os ditos pequenos frutos, como amora-preta, mirtilo e framboesa, ainda há limitação de mercado (Fachinello, 1998; Pagot \& Hoffmann, 2003), provavelmente, devido à pouca oferta de produto no mercado brasileiro; a fragilidade da fruta e reduzida conservação em póscolheita (Antunes et al., 2003; Antunes et al., 2006 ab); a falta de conhecimento sobre as qualidades nutracêuticas destas pequenas frutas (Giongo et al., 2006); e falta de indicação de variedades mais adaptadas às diferentes condições edafoclimáticas existentes no Brasil, o que pode ser sanado através de trabalhos regionais de teste de adaptação de variedades (Peruzzo et al, 1995; Antunes et al., 2000 a).

Dentre as variedades que mais se adaptam às condições edafoclimáticas do Planalto de Poços de Caldas, estão 'Brazos', 'Tupy', 'Guarani' e 'Comanche', com produções superiores a 16 toneladas por ha (Antunes et al., $2000 \mathrm{ab}$ ).

Sendo planta exigente em frio (Wrege \& Herter, 2004), os aspectos fenológicos da amoreira-preta podem variar de ano para ano em função de esta exigência em frio ter sido ou não satisfeita. Além de aspectos climáticos, fatores inerentes à espécie e/ou variedade podem afetar o comportamento da planta (Antunes et al., 2000b).

Nas condições do Rio Grande do Sul (RS), a variedade de amoreira-preta Ébano inicia a floração na segunda quinzena de outubro, estendendo-se até o início de novembro, sendo que o período de colheita vai de meados de dezembro a início de fevereiro, com produtividade de 5,9 t/ha (Bassols \& Moore, 1981; Nunes \& Gonçalves, 1981; EMBRAPA, 1981). Já em Jundiaí, Estado de São Paulo, Martins \& Pedro Júnior (1999) encontram valores de produtividade inferiores para 'Ébano' (2,9 t/ha). Segundo Raseira et al. (1992), a variedade Caingangue, em Pelotas (RS), tem plena floração na primeira dezena de outubro e período de produção da segunda dezena de novembro à segunda dezena de dezembro, com produção média de 3,45 kg/planta e peso médio de 5,6 g/fruto.

A floração da amoreira-preta 'Tupy' no Rio Grande do Sul dáse da terceira dezena agosto à segunda dezena de setembro, e colheita da terceira dezena de novembro à segunda de dezembro (Santos \& Raseira, 1988). Já 'Guarani' tem floração durante todo o mês de setembro e primeira dezena de outubro, com período de colheita estendendo-se pelo o mês de dezembro (Santos \& Raseira, 1988). Em

\footnotetext{
(Trabalho 18-2006). Recebido: 24-02-2006. Aceito para publicação: 06-10-2006.

2 Eng. Agr., Dr., Embrapa - Centro de Pesquisa Agropecuária de Clima Temperado, CP 403, 96001-970, Pelotas-RS, Bolsista CNPq, e-mail: antunes@cpact.embrapa.br

${ }^{3}$ Eng. Agr, Dr. Bolsista RD/CNPq. Embrapa - Centro de Pesquisa Agropecuária de Clima Temperado, CP 403, 96001-970, Pelotas-RS, Bolsista CNPq, email: trevisan@cpact.embrapa.br

${ }^{4}$ Eng. Agr, Doutorando Universidade Federal de Pelotas- UFPel, Pelotas-RS, Bolsista CAPES, e-mail: franzon@cpact.embrapa.br
} 
contrapartida, Peruzzo et al. (1995) observaram, em Videira, Estado de Santa Catarina (SC), que 'Brazos' iniciou a floração na segunda dezena de setembro e 'Caingangue' na terceira dezena. 'Tupy', 'Comanche', 'Guarani', Cherokee' e 'Ébano' tiveram floração distribuída pelo mês de outubro. Sendo que o período de colheita estendeu-se da segunda dezena de novembro à terceira dezena de janeiro. Em Caldas (MG), observou-se início de floração no final de agosto e início de setembro para 'Brazos' e 'Comanche', sendo as demais entre setembro e outubro, com produção da segunda quinzena de outubro a fevereiro (Antunes et al., 2000b).

Percebe-se, assim, que a produção de amora-preta no Brasil estende-se de outubro a fevereiro, não havendo oferta interna do produto fora deste intervalo, período este que pode representar oportunidade àqueles que produzem nesta época do ano, o que poderá refletir-se em remuneração da fruta maior que na época normal de safra. Na região de Pelotas, na safra 2005-2006, esta remuneração foi de 1,20 a 1,50 real para frutas destinadas à industrialização e de 3,00 reais $/ \mathrm{kg}$ àquelas destinadas ao mercado in natura, vendido a granel. Para produtos embalados em cumbucas de 300 gramas, o valor foi superior a 10 reais o quilo. Estas informações são corroboradas pelos dados apresentados por Antunes (2002), onde a safra gaúcha, que se inicia em outubro, pode atingir US\$2,54/kg, reduzindo paulatinamente a 1,90,1,52 e 1,44, respectivamente, em novembro, dezembro e janeiro, podendo haver alguma oferta sazonal, como em agosto de 1997, em que o preço do quilo da amora-preta alcançou US\$ 4,58, com frutas provenientes de São Paulo. A produção fora dos picos de oferta da fruta poderá ser uma opção bastante interessante economicamente, como se verifica para outras frutas, como, por exemplo, o morango produzido entre janeiro e março, que alcança preços de mais do dobro da safra normal.

Verifica-se, em grande parte dos Estados da região Sudeste brasileira, que chuvas de verão se encerram no final de março, dando início a um período de outono/inverno seco e com temperaturas amenas (Amorim et al., 2005), período favorável à produção de frutos, principalmente em virtude da redução de podridões.

Em relação à técnica de poda verde ou de verão, trabalhos com pessegueiro têm concluído que esta técnica de manejo incrementa a coloração vermelha da epiderme dos frutos e melhora a entrada de luz na subcopa (Coutinho et al., 2005). Já em videira, cv Syrah, tem-se utilizado a técnica para indução de produção extemporrânea no sul de Minas Gerais (Amorim et al., 2005).

Desta forma, o objetivo deste trabalho foi o de avaliar a influência da poda de verão na produção extemporânea de variedades de amoreira-preta no Planalto de Poços de Caldas.

\section{MATERIAL E MÉTODOS}

Este trabalho foi desenvolvido na coleção de variedades de amoreira-preta mantidas, desde de julho de 1996, na Fazenda Experimental da EPAMIG em Caldas (FECD), durante os anos agrícolas 1997-1998, 1998-1999 e 1999-2000. Caldas situa-se a 21 $55^{\prime}$ latitude sul e $40^{\circ}$ longitude oeste, a $1.150 \mathrm{~m}$ de altitude. A região apresenta temperatura média anual de $19^{\circ} \mathrm{C}$, com média das mínimas de $13^{\circ} \mathrm{C}$ e das máximas de $26^{\circ} \mathrm{C}$, umidade relativa de $75 \%$, precipitação pluviométrica total anual de $1.500 \mathrm{~mm}$ e insolação anual de 1.816 horas. O tipo de solo onde se encontra instalada a coleção de variedades é do tipo Litossolo Câmbico (Gonçalves, 1996).

As variedades de amoreira-preta estudadas foram: Comanche, Ébano, Caingangue, Cherokee, Guarani, Tupy e Brazos, e uma seleção denominada 97. As avaliações foram realizadas a partir do ciclo produtivo de 1997-1998. As plantas foram conduzidas em espaldeira dupla, num espaçamento de plantio de 0,70 x 3,0 metros. O pomar não foi irrigado. Os tratos culturais aplicados foram os preconizados por Bassols (1980) e EMBRAPA (1989). O delineamento foi o inteiramente casualizado, com 5 repetições e uma planta por repetição. As análises estatísticas foram feitas usando o programa SISVAR (Ferreira, 2000).

A poda de verão foi realizada após o período de colheita da safra de 1998-1999, ou seja, 23-02-99. Nesta operação, foram retirados os ramos senescentes de produção e reduzidos aqueles do surto de crescimento do ano, a altura de $10 \mathrm{~cm}$ acima do arame de condução. Neste trabalho, foram avaliados período de colheita, produção por planta, produção estimada por hectare e peso médio de frutos.

\section{RESULTADOS E DISCUSSÃO}

Verificou-se que houve, entre a $1^{\mathrm{a}}$ (primeira) safra de amorapreta (1997-1998) e a segunda (1998-1999), uma tendência de ascensão em produção (Tabelas 1; 2 e 3), onde se destacaram as variedades Brazos, Tupy, Guarani e Comanche, com produtividades superiores a $16 \mathrm{t} / \mathrm{ha}$, como verificado por Antunes et al. (2000a). Estes índices de produtividade são superiores àqueles relatados por Peruzzo et al. (1995), em que citam como excelente a produtividade de $10 \mathrm{t} / \mathrm{ha}$.

Com a poda verde (ou de verão) aplicada entre as safras de 1998-1999 e 1999-2000, observou-se um estímulo à brotação de novos ramos e, com isto, houve a diferenciação e floração para algumas variedades. Apenas três variedades não produziram extemporaneamente (Tabela 4) e apenas Tupy (2,93 t/ha) e Comanche $(3,26 \mathrm{t} / \mathrm{ha})$ produziram satisfatoriamente para o período, uma vez que, como se observa, a produção concentrou-se entre os meses mais

TABELA 1 - Valores médios das características produção por plantas e por hectare, período de colheita e peso médio de frutos. Caldas - MG.

\begin{tabular}{lcccc}
\hline Safra & $\begin{array}{c}\text { Produção/planta } \\
(\mathrm{kg})\end{array}$ & $\begin{array}{c}\text { Produção/ha } \\
\text { (toneladas) }\end{array}$ & $\begin{array}{c}\text { Período de } \\
\text { Colheita (dias) }\end{array}$ & $\begin{array}{c}\text { Peso Médio de } \\
\text { Fruto (g) }\end{array}$ \\
\hline $1997-1998$ & $1,74 \mathrm{a}$ & $7,96 \mathrm{a}$ & $86,25 \mathrm{ab}$ & $5,22 \mathrm{a}$ \\
$1998-1999$ & $2,68 \mathrm{a}$ & $12,79 \mathrm{a}$ & $91,12 \mathrm{a}$ & $5,82 \mathrm{a}$ \\
1999 & $0,17 \mathrm{~b}$ & $0,82 \mathrm{~b}$ & $27,12 \mathrm{c}$ & $2,85 \mathrm{~b}$ \\
$1999-2000$ & $2,03 \mathrm{a}$ & $9,46 \mathrm{a}$ & $76,25 \mathrm{~b}$ & $5,46 \mathrm{a}$ \\
\hline Variedade & & & & $5,21 \mathrm{ab}$ \\
\hline Brazos & $2,93 \mathrm{a}$ & $13,22 \mathrm{a}$ & $51,25 \mathrm{~b}$ & $6,40 \mathrm{a}$ \\
Tupy & $2,22 \mathrm{ab}$ & $10,58 \mathrm{ab}$ & $80 \mathrm{a}$ & $4,32 \mathrm{ab}$ \\
Guarani & $2,85 \mathrm{a}$ & $13,59 \mathrm{a}$ & $77 \mathrm{a}$ & $4,11 \mathrm{ab}$ \\
Caingangue & $1,43 \mathrm{ab}$ & $6,80 \mathrm{ab}$ & $80,75 \mathrm{a}$ & $3,76 \mathrm{~b}$ \\
Cherokee & $0,59 \mathrm{~b}$ & $2,85 \mathrm{~b}$ & $71,75 \mathrm{ab}$ & $4,46 \mathrm{ab}$ \\
Seleção 97 & $0,52 \mathrm{~b}$ & $2,07 \mathrm{~b}$ & $57,75 \mathrm{ab}$ & $3,63 \mathrm{~b}$ \\
Ébano & $0,62 \mathrm{~b}$ & $2,97 \mathrm{~b}$ & $72,5 \mathrm{~b}$ & $4,82 \mathrm{ab}$ \\
Comanche & 2,09 & $9,98 \mathrm{ab}$ & $6,5 \mathrm{ab}$ & 4,59 \\
\hline Média & 1,66 & 7,76 & 15,06 & 23,12 \\
\hline C.V. & 48,70 & 49,12 & & \\
\hline
\end{tabular}


TABELA 2 - Características de produção de amora-preta para a safra de 1997-1998. Caldas - MG.

\begin{tabular}{lcccccc}
\hline \multirow{2}{*}{ Variedade } & Produção & & & \multicolumn{2}{c}{ Colheitas } & Peso \\
\cline { 2 - 3 } & $\begin{array}{c}\mathrm{kg} / \\
\text { planta }\end{array}$ & $\mathrm{t} / \mathrm{ha}$ & $\begin{array}{c}\text { Período de colheita } \\
\text { (dias) }\end{array}$ & Primeira & Última & médio $(\mathrm{g})$ \\
\hline Brazos & 3,43 & 13,36 & 76 & $17-11$ & $05-01$ & 6,93 \\
Tupy & 1,73 & 8,25 & 87 & $11-11$ & $05-02$ & 7,54 \\
Guarani & 2,70 & 12,87 & 84 & $14-11$ & $05-02$ & 4,47 \\
Caingangue & 1,89 & 8,99 & 92 & $6-11$ & $05-02$ & 4,69 \\
Cherokee & 0,81 & 3,88 & 81 & $17-11$ & $05-02$ & 4,08 \\
Seleção 97 & 0,43 & 2,05 & 81 & $17-11$ & $05-02$ & 5,00 \\
Ébano & 1,17 & 5,56 & 84 & $14-11$ & $05-02$ & 4,49 \\
Comanche & 1,83 & 8,73 & 105 & $24-10$ & $05-02$ & 4,59 \\
\hline
\end{tabular}

TABELA 3 - Características de produção de amora-preta para a safra de 1998-1999. Caldas - MG.

\begin{tabular}{|c|c|c|c|c|c|c|}
\hline \multirow[b]{2}{*}{ Variedade } & \multicolumn{2}{|c|}{ Produção } & \multirow[b]{2}{*}{$\begin{array}{l}\text { Período de colheita } \\
\text { (dias) }\end{array}$} & \multicolumn{2}{|c|}{ Colheitas } & \multirow[b]{2}{*}{$\begin{array}{c}\text { Peso } \\
\text { médio }(\mathrm{g})\end{array}$} \\
\hline & $\begin{array}{c}\mathrm{kg} / \\
\text { planta }\end{array}$ & $\mathrm{t} / \mathrm{ha}$ & & Primeira & Última & \\
\hline Brazos & 5,30 & 25,24 & 81 & $27-10$ & $29-01$ & 7,40 \\
\hline Tupy & 3,63 & 17,29 & 102 & $27-10$ & 05-02 & 7,25 \\
\hline Guarani & 4,77 & 22,72 & 98 & $03-11$ & 08-02 & 5,32 \\
\hline Caingangue & 2,06 & 9,8 & 103 & $29-10$ & 08-02 & 5,02 \\
\hline Cherokee & 0,91 & 4,36 & 90 & $11-11$ & 08-02 & 4,34 \\
\hline Seleção 97 & 0,66 & 3,15 & 81 & $20-11$ & 08-02 & 6,83 \\
\hline Ébano & 0,68 & 3,26 & 83 & 03-11 & 08-02 & 4,75 \\
\hline Comanche & 3,47 & 16,52 & 91 & $27-10$ & $25-01$ & 5,71 \\
\hline
\end{tabular}

TABELA 4 - Características de produção de amora-preta para a safra de 1999. Caldas - MG.

\begin{tabular}{|c|c|c|c|c|c|c|}
\hline \multirow[b]{2}{*}{ Variedade } & \multicolumn{2}{|c|}{ Produção } & \multirow[b]{2}{*}{$\begin{array}{l}\text { Período de colheita } \\
\text { (dias) }\end{array}$} & \multicolumn{2}{|c|}{ Colheitas } & \multirow[b]{2}{*}{$\begin{array}{c}\text { Peso } \\
\text { médio }(\mathrm{g})\end{array}$} \\
\hline & $\begin{array}{c}\mathrm{kg} / \\
\text { planta }\end{array}$ & $\mathrm{t} / \mathrm{ha}$ & & Primeira & Última & \\
\hline Brazos & - & - & - & - & - & - \\
\hline Tupy & 0,62 & 2,93 & 37 & - & $03-08$ & 4,11 \\
\hline Guarani & 0,02 & 0,11 & 27 & $28-06$ & 03-08 & 2,63 \\
\hline Caingangue & 0,03 & 0,16 & 27 & $05-07$ & $26-07$ & 2,16 \\
\hline Cherokee & 0,03 & 0,16 & 29 & $28-06$ & $23-07$ & 2,34 \\
\hline Seleção 97 & - & - & - & - & - & - \\
\hline Ébano & - & - & - & - & - & - \\
\hline Comanche & 0,69 & 3,26 & 17 & $17-06$ & 03-07 & 3,63 \\
\hline
\end{tabular}

TABELA 5 - Características de produção de amora-preta para a safra de 1999-2000. Caldas - MG.

\begin{tabular}{|c|c|c|c|c|c|c|}
\hline \multirow[b]{2}{*}{ Vari edade } & \multicolumn{2}{|c|}{ Produção } & \multirow[b]{2}{*}{$\begin{array}{l}\text { Período de colheita } \\
\text { (dias) }\end{array}$} & \multicolumn{2}{|c|}{ Colheitas } & \multirow[b]{2}{*}{$\begin{array}{c}\text { Peso } \\
\text { médio }(\mathrm{g})\end{array}$} \\
\hline & $\begin{array}{c}\mathrm{kg} / \\
\text { planta }\end{array}$ & $\mathrm{t} / \mathrm{ha}$ & & Primeira & Última & \\
\hline Brazos & 3,00 & 14,28 & 48 & $03-11$ & $20-12$ & 6,51 \\
\hline Tupy & 2,90 & 13,86 & 94 & 09-11 & $11-02$ & 6,70 \\
\hline Guarani & 3,92 & 18,67 & 99 & $05-11$ & $11-02$ & 4,89 \\
\hline Caingangue & 1,74 & 8,28 & 101 & $03-11$ & $11-02$ & 4,57 \\
\hline Cherokee & 0,63 & 3,02 & 87 & $12-11$ & $07-02$ & 4,30 \\
\hline Seleção 97 & 1,00 & 4,76 & 69 & $16-11$ & 24-01 & 6,02 \\
\hline Ébano & 0,65 & 3,09 & 43 & $30-12$ & $11-02$ & 5,31 \\
\hline Comanche & 2,40 & 11,43 & 69 & 03-01 & $10-01$ & 5,38 \\
\hline
\end{tabular}




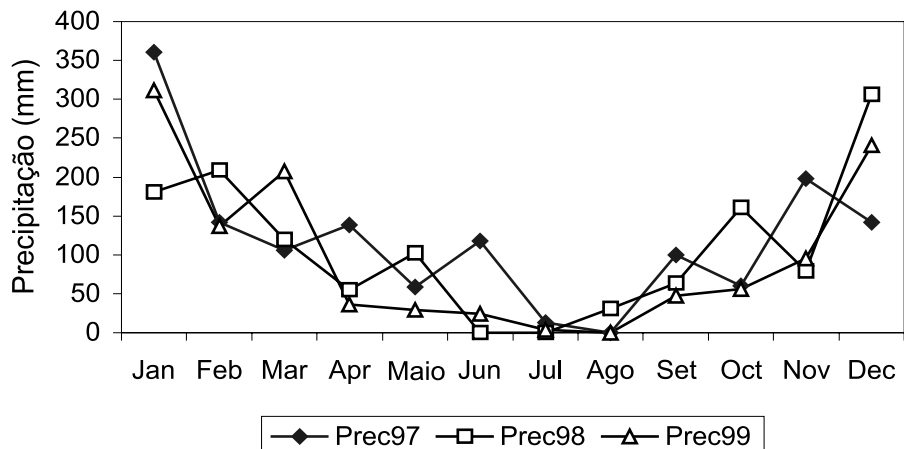

FIGURA 1 - Precipitação pluvial (mm) durante os anos de 1997, 1998 e 1999, em Caldas - MG.

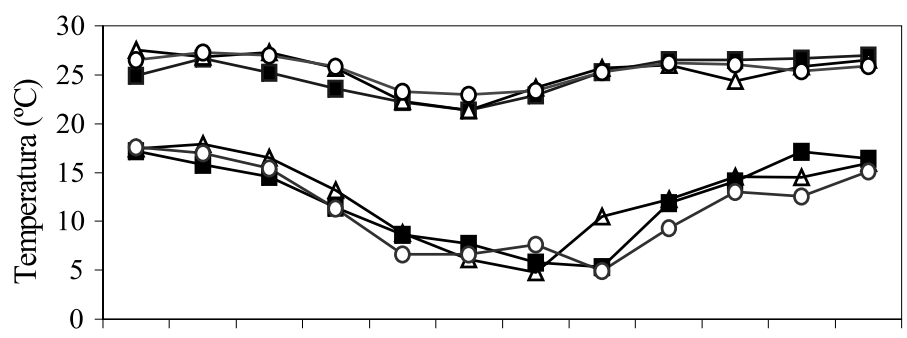

Jan Feb Mar Apr Maio Jun Jul Ago Set Oct Nov Dec

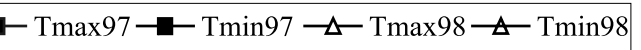

- - Tmax $99-0-T \min 99$

FIGURA 2 - Representação gráfica das médias de temperatura máxima e mínima durante os anos de 1997, 1998 e 1999, em Caldas - MG.

frios do ano e com condições hídricas desfavoráveis (Figuras 1 e 2). Segundo Amorin et al. (2005), que trabalhando com produção extemporânea de videira cultivar Syrah, no sul de Minas, verificou a redução da evapotranspiração, devida à redução da temperatura e diminuição do fotoperíodo, e também a própria redução da área foliar das plantas, que, ao final do ciclo, já demonstravam sinais de senescência, em período análogo ao deste trabalho. Estas características ecofisiológicas, típicas de plantas de clima temperado, afetaram sobremaneira a produção das variedades de amora-preta estudadas neste ensaio. Gaskell (2000) verificou que variedades de mirtilo do grupo highbush produziam fora de época, entretanto com redução do peso dos frutos e do número de frutos por planta. Apenas a variedade Sharpblue produziu frutos maiores que na colheita principal. Esse mesmo autor diz que é possível a produção fora de época desde que haja um manejo bem feito das práticas de poda e a combinação com variedades adequadas.

Para o período de colheita, observou-se uma variação de 76 a 105 dias na safra de 1997-1998 (média de 86,25 dias) e de 81 a 103 dias para safra de 1998-1999 (média de 91,12 dias) (Tabelas 1; 2 e 3), o que dá ao produtor um período bastante amplo de safra e oferta de fruta ao mercado. As colheitas foram iniciadas na primeira dezena de novembro e estendendo-se à primeira dezena de fevereiro em ambas as safras, informações corroboradas por Antunes et al. (2000 b).

Com a poda de verão, a colheita no outono de 1999 variou de 17 dias para Comanche até 37 dias para Tupy. O início de colheita concentrou-se no final da segunda dezena de junho a início de agosto (Tabela 4). A colheita concentrou-se num período de baixa oferta de frutas frescas no mercado, especialmente as de clima temperado, o que poderia ser uma oportunidade de negócios para o produtor. Já na colheita de 1999-2000 (Tabela 5), a variação foi de 48 a 101 dias de safra, sendo que Brazos apresentou o menor período e Caingangue o maior. Das variedades que produziram extemporaneamente, apenas Comanche apresentou redução do período de safra primavera/verão, com 69 dias (Tabela 4) se comparada à safra de 1997-1998, com 105 dias e 1998-1999, com 91 dias (Tabelas 1 e 2).

Na safra extemporânea de 99, para a característica peso médio dos frutos, houve uma produção de frutos com peso abaixo da média característica das variedades, período de colheita bastante reduzido e também baixa produtividade (Tabelas 1 e 4). Apesar disto, estas características foram superiores às encontrados por Martins \& Pedro Júnior (1999) para ‘Ébano' (2,9 t/ha), em Jundiaí, São Paulo, na safra de primavera/verão, em relação a 'Tupy' e 'Comanche' (Tabela 4). 'Brazos', 'Ébano' e a Seleção 97 não apresentaram produção extemporrânea no período avaliado. A variedade Ébano foi a única sem espinho envolvida no estudo, cujas características são descritas por Bassols \& Moore (1981).

A variação de peso dos frutos foi pequena entre as safras ditas de época, como o caso de Tupy 7,54; 7,25 e 6,70 gramas para safras de 1997-1998, 1998-1999 e 1999-2000. Em Santa Catarina, Peruzzo et al. (1995) obtiveram, na coleção de variedades da EPAGRI de Videira, peso médio de frutos para 'Brazos' (3,1g), 'Tupy' (5,6g), 'Caingangue' (4,4 g), 'Guarani' (4,1 g), 'Comanche' (3,8 g), 'Cherokee' (4,0 g) e 'Ébano' (2,4 g). Em se tratando de produção extemporânea, houve redução do peso das variedades, onde 'Tupy' $(4,11 \mathrm{~g})$, 'Guarani' (2,63 g), 'Cainguangue' (2,16 g), 'Cherokee' (2,34 g) e 'Comanche' (3,63 g) ficaram abaixo do descrito por Bassols (1980), Santos \& Raseira (1988), Raseira \& Santos (1992), Antunes (2002) e Antunes \& Raseira (2004), comprometendo um dos atributos de qualidade, que é o tamanho da fruta.

Durante o período de safra de 1999-2000, posterior à produção extemporânea, houve redução da produção por planta, redução do período de colheita para quase a totalidade das variedades, além da redução do peso médio dos frutos (Tabelas 3 e 4), em relação à safra de 1998-1999, mesmo não havendo diferença significativa (Tabela 1).

Além do possível estresse provocado pela produção fora de época, devido à poda de verão, as condições climáticas podem ter influenciado no período, visto que as temperaturas mínimas no ano de 1999 mantiveram-se desfavoráveis ao desenvolvimento das plantas, especialmente as do mês de maio, com cerca de $2^{\circ}$, em média, abaixo do registrado nos demais anos de avaliação (Figura 2). Além disso, o índice pluviométrico, entre abril e maio daquele ano, foi abaixo dos demais anos de avaliação (Figura 1). Verificou-se que no ano de 99 o índice pluviométrico foi bastante baixo, principalmente a partir do desenvolvimento dos novos brotos, já em agosto (Figura 1), o que pode ter contribuído pela redução da produtividade e peso médio de fruto na safra de 1999-2000, embora significativa (Tabela $1)$.

\section{CONCLUSÕES}

1) Concluiu-se que a produção extemporânea (safra 1999), induzida pela poda de verão, influiu negativamente em todas as características avaliadas.

2) Entre as variedades que mais produziram fora de época, 'Comanche' (3,26 t/ha) e 'Tupy' (2,93 t/ha) foram as que mais se destacaram.

3) Não houve produção fora de época para 'Brazos', 'Ébano' e a Seleção 97.

4) A produção extemporânea não prejudicou significativamente a produção da safra de 1999-2000, por área, por planta e peso médio de fruto. 


\section{REFERÊNCIAS}

AMORIM, D.A. de; FAVERO, A.C.; REGINA, M. de A. Produção Extemporânea de videira, cv. Syrah, nas condições do Sul de Minas Gerais. Revista Brasileira de Fruticultura, Jaboticabal, v.27, n.2, p.327-331, 2005.

ANTUNES, L. E. C. Amora-preta: nova opção de cultivo no Brasil. Ciência Rural, Santa Maria, v.32, n.1, p.151-158, 2002.

ANTUNES, L.E.C. Potencial de produção de pequenas frutas em diferentes regiões do Sul do Brasil. In: ENCONTRO NACIONAL DE FRUTICULTURA DE CLIMA TEMPERADO DO SUL DO BRASIL, 8., 2005, Caçador. Anais... Caçador: EPAGRI, 2005. v. 1, p. 61-63.

ANTUNES, L.E.C.; CHALFUN, N. N. J.; REGINA, M. de A.; HOFFMANN, A. Blossom and ripening periods of blackberry varieties in Brazil. Journal American Pomological Society, Virginia, v.54, n.4, p.164-168, 2000 b.

ANTUNES, L.E.C.; CHALFUN, N.N.J.; REGINA, M. de A.; DUARTE FILHO, J. Fenologia e produção de variedades de amora-preta nas condições do Planalto de Poços de Caldas-MG. Revista Brasileira de Fruticultura, Jaboticabal, v.22, n.1, p. 89-95, 2000 a.

ANTUNES, L.E.C.; DUARTE FILHO, J. SOUZA, C.M. de Conservação pós-colheita de frutos de amoreira-preta. Pesquisa Agropecuária Brasileira, Brasília, v.38, n. 3, p. 413-419, 2003.

ANTUNES, L.E.C.; GONÇALVES, D.E.; TREVISAN, R. Alterações da atividade da poligalacturonase e pectinametilesterase em amora-preta (Rubus spp.) durante o armazenamento. Revista Brasileira de Agrociência, Pelotas, v. 12, n. 1, p. 63-66, 2006 a.

ANTUNES, L.E.C.; GONÇALVES, D.E.; TREVISAN, R. Alterações de compostos fenólicos e pectina em pós-colheita de frutos de amora-preta. Revista Brasileira de Agrociência, Pelotas, v. 12, n. 1, p. 57-61, 2006 b.

ANTUNES, L.E.C.; RASEIRA, M.do C.B. Aspectos técnicos da cultura da amora-preta. Pelotas: Embrapa Clima Temperado, 2004. 54 p. (Documento, 122)

BASSOLS, M. do C. A Cultura da amora preta. Pelotas: EMBRAPA/ UEPAE de Cascata. 1980. 11 p. (Circular Técnica, 4).

BASSOLS, M. do C. M.; MOORE, J.N. 'Ébano' thornless blackberry. Hortscience, Alexandria, v.16, n.5, p. 686-687, 1981.

COUTINHO, E.F.; FRANCHINI, E.R.; CAMELATTO, D.; ULGUIM, E.B. Relação entre a poda verde e o uso de material refletivo com a qualidade de pêssego 'Eldorado'. Pelotas: Embrapa Clima Temperado, 2005. 21 p. (Documentos, 134).

DUARTE FILHO, J.; ANTUNES, L.E.C.; ROUDEILLAC, P. Le Brésil ramène as fraise. Culture léguminere, Paris, n. 62, p. 20-26, 2001.
EMBRAPA. Amora-Preta: sistema de produção. Pelotas: CNPFT, 1989.2p.

EMBRAPA. Lançamento de cultivares. Pelotas: UEPAE de Cascata, 1981. 16 p. (Documentos, 1)

FACHINELLO, J.C. Situazione e prospecttive della frutticoltura temperata in Brasile. Rivista de Frutticoltura, Bologna, n. 3, p. $39-44,1998$.

FERREIRA, D.F. Manual do sistema Sisvar para análises estatísticas. Lavras: UFLA, 2000. $66 \mathrm{f}$.

GASKELL, M. A new alternative crop for Califórnia. Davis, p. 1-4, 2000. Disponível em: <http://www.sfc.ucdavis.edu/research/ blueberryupdate.html (1 of 4) [22-5-2006 18:15:49] >. Acesso em: 22 maio 2006

GIONGO, L.; ZUIN, N.; MATTINI, F. Dal Trentino uno sgaurdo internazionale su fragola e piccolo frutti: analisi e prospecttive del mercato fresco. Rivista di Frutticoltura, Bologna, v.65, n. 4, p. 43-48, Aprile, 2006.

GONÇALVES, C.A.A. Comportamento da cv. folha de figo (Vitis labrusca L.) sobre diferentes porta-enxertos de videira. 1996. 45 f. Dissertação (Mestrado em Agronomia/Fitotecnia)Universidade Federal de Lavras, Lavras, 1996.

MARTINS, F.P.; PEDRO JÚNIOR, M.J. Influência do espaçamento na produtividade da amora-preta, cv. Ébano, em Jundiaí. Bragantia. Campinas, v. 58, n. 2, p. 317-321, 1999.

NUNES, R. de P.; GONSALVES, R. S. (Coord.) Novas cultivares. Brasília: EMBRAPA, 64p. 1981. (Documento, 8)

PAGOT, E.; HOFFMANN, A. Produção de pequenos frutos. In: SEMINÁRIO BRASILEIRO SOBRE PEQUENAS FRUTAS, 1 ., 2003, Bento Gonçalves: Embrapa Uva e Vinho, 2003. p.7-15. (Documentos, 37)

PERUZZO, E.L.; DALBÓ, M.A.; PICCOLI, P.S. Amora-preta: variedades e propagação. Agropecuária Catarinense, Florianópolis, v.8, n.3, p.53-55, 1995.

RASEIRA, A.; SANTOS, A.M. dos; RASEIRA, M. do C. B. Caingangue, nova cultivar de amora-preta para consumo in natura. Horti Sul, Pelotas, v.2, n.3, p11-12,1992.

SANTOS, A.M. dos; RASEIRA, M. do C. B. Lançamento de cultivares de amora-preta. Pelotas: EMBRAPA-CNPFT, 1988. Não paginado. (EMBRAPA. Informativo, 23).

WREGE, M.S.; HERTER, F.G. Condições de clima. In: ANTUNES, L.E.C.; RASEIRA, M. do C.B. Aspectos técnicos da cultura da amora-preta. Pelotas: Embrapa Clima Temperado, 2004. 54 p. (Documento, 122) 